to live to request and self-administer lethal medication prescribed by a physician. Oregon was the first state to adopt such a law, in 1997. Some 341 residents used it to hasten their deaths in 2007. Unlike Canada, the Netherlands, Belgium and Switzerland have decriminalized assisted suicide.

Aboriginal curriculum: The Association of Faculties of Medicine of Canada and Indigenous Physicians Association of Canada have unveiled a new Aboriginal health curriculum framework for medical schools (CMAJ 2008;178 [13]:1650) that familiarizes physicians with the precepts of "cultural safety, which encompasses concepts of cultural awareness, sensitivity and competence", as well as "the additional skill of self-reflection," (www.afmc.ca/socialaboriginal-health-e.php).

Awards: University of Ottawa professor of medicine Dr. Peter Tugwell has been named recipient of the prestigious Canadian Institutes of Health Research Michael Smith Prize as Canada's 2008

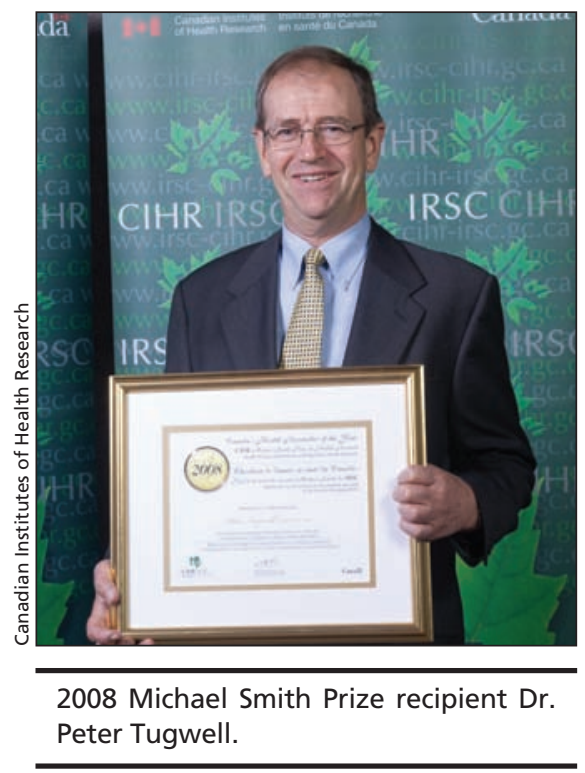

Health Researcher of the Year for Health Services and Systems and Population Health Research. Tugwell, who is also chair of the CMAJ Oversight Committee, received a medal and a research grant of $\$ 100000$ per year for 5 years. - Wayne Kondro, CMAJ

DOI:10.1503/cmaj.081940

\title{
Perfect predilections
}

$\mathrm{T}$ here's a glint in her eyes as she talks about the appeal of family practice - daily diversity, pedagogical and international doors opened, and, of course, the opportunity to occasionally perform a bit of surgery.

"That is what I love about family medicine. You can invent yourself in a whole lot of directions," says Dr. Diane L. Kelsall, recently minted $C M A J$ Deputy Editor, Clinical Practice. "And I just love surgical procedures. If there is anything I can whack out, or fix, on my patients, within my realm, I will do."

A perfect predilection, particularly if the primary task you've been charged with is complete dissection and subsequent reconstruction of CMAJ's Practice section to make it more useful for practitioners.

CMAJ Editor-in-Chief Dr. Paul Hébert says no one is better qualified to undertake the overhaul. "As the former editor of Canadian Family Physician, she's very familiar with the needs of practitioners. Diane's highly respected in the field of family medicine and will bring that voice to the journal."

Kelsall envisions an expanded practice section and a host of new online resources for physicians on the CMAJ website. "When a physician opens the journal, there has to be something in it that they can look at and say, 'I can do something about this tomorrow.",

The plan is to distill the plethora of research that exists on medical conditions, diagnostics and therapies into "practical" chunks. "A practising physician does not have the time to sift through the last 200 research papers on a particular topic. What we're hoping to do is to do that sifting for them."

A graduate of the University of Toronto, the 46-year-old contemplated a surgical residency before deciding on family practice. She later completed a family and community medicine fellowship, a Masters of Education and then moved into a series of staff physician positions in Kingston, Ottawa and Edmonton before returning to Toronto, where she's now on staff at Mount Sinai Hospital and an assistant professor of family and community medicine at her alma mater. She also spent 2 years

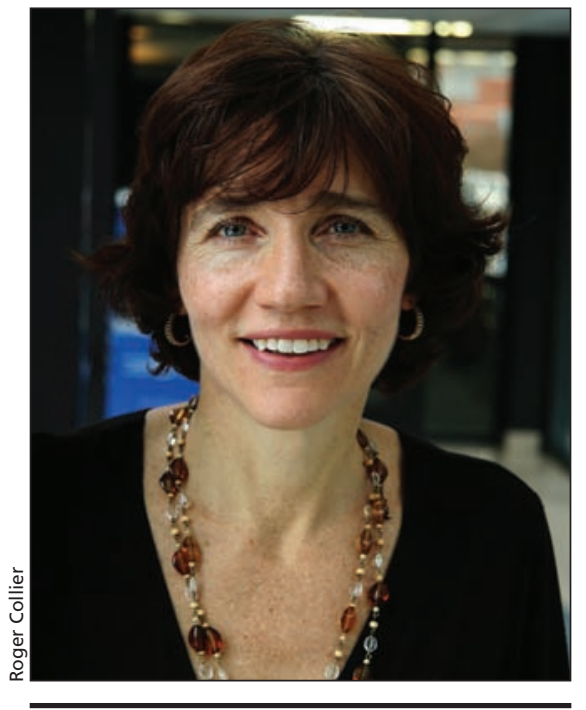

Dr. Diane L. Kelsall is CMAJ's new Deputy Editor, Clinical Practice.

in England (2004-2006) helping establish an international medical charity.

Kelsall caught the editing bug when she was asked to contribute to a church newsletter and soon parlayed her fondness for language into a 10-year stint as editor of the Institute of Clinical Evaluative Science's quarterly, informed. She served as editor of Canadian Family Physician from 2006 until joining CMAJ in November 2008.

The opportunity to move to a journal with a broader reach was irresistible, says Kelsall. "What is interesting to a family physician or a generalist is interesting across the board. If you're going to do an article on a topic, whether a subspecialist or a generalist, we need to be informed, broadly. So to me, it was just a marvelous opportunity to work with a larger audience."

A voracious reader, eager traveller and avid walker — "about 4 miles a day" - Kelsall is married to Carsten Hennings, assistant professor of business at Tyndale University College \& Seminary, and the mother of 11-year-old Rachel. The long-time Toronto resident claims she didn't feel compelled to contact the armed forces when $4 \mathrm{~cm}$ of snow fell on Ottawa shortly after her arrival. "I was born in Winnipeg," she explains. Wayne Kondro, CMAJ

DOI:10.1503/cmaj.081938 